\title{
Increasing the Effeciency of Laser Marking Ofaluminum Alloys by Double Writing of the Symbols
}

\author{
Atanas Atanasov \\ TU - Sofia, Plovdiv Branch \\ Plovdiv, Bulgaria \\ laser@gbg.bg
}

\begin{abstract}
A comparison is made between samples marked by writing letters and symbols once, with these marked by twice but writing with two times greater velocity. As a consequence of the sharp decreasing of the main characteristic of the material -its reflective index, in the second case we received an enhancement of the effectiveness of the laser marking, decreasing energy use at the same time. Experimental studies have been carried out with a $\mathrm{CuBr}$ (copper bromide vapour) laser for specific mechanical engineering details.
\end{abstract}

Keywords - double writing, aluminium, aluminium alloys, effectiveness, laser marking, copper bromide vapour laser.

\section{INTRODUCTION}

In recent years, the laser marking is widely used for a number of Aluminium devices and products - medical instruments, machine parts in aerospace, electronics and avionics, machine-building details, etc. [2, 4, 5] The requirements for the label regarding its quality, speed and efficiency of production [3] are constantly increasing. In order to meet all these challenges, it is necessary to carry out research, leading to the optimization and increasing the efficiency of the technological process of laser marking. The purpose of this report is to summarize and analyse the methods of laser marking by double or multiple writing and to show their capabilities. Specific examples for optimization of the laser marking process with various methods of industrial products are also shown, using a copper bromide vapor $(\mathrm{CuBr})$ laser included in a MOPA (Master Oscillator Power Amplifier) system and optical galvo scanhead.

\section{MATERIALS AND METHODS}

In addition to the traditional laser marking, other marking methods have recently been applied, leading to a

\author{
Angel Lengerov \\ TU - Sofia, Plovdiv Branch \\ Plovdiv, Bulgaria \\ anlengerov@abv.bg
}

better design and aesthetics of the product - by doublewriting the symbols, by hatching and by wobbling. The aim of the present research is to show the possibilities of these ways of marking and to determine some optimal intervals of the main parameters of the $\mathrm{CuBr}$ laser and the technological process for marking of aluminium details.

\section{A. Marking by double-writing the symbols}

This method of laser marking was proposed and discussed in [1]. For its realization it is necessary for the laser to have a power density around the threshold of destruction of the material. At the first writing along the contour, the reflection coefficient of the material in the impact zone decreases (due to the occurrence of structural changes or oxidation of the surface). Repeatedly passing the same contour absorbs a significantly larger part of the energy ( up to 75 - 85\%) compared to the first discharge. The energy absorbed by the heat source moving on the surface of the article is sufficient to form a contrast marking on it, and in some cases to form a channel with the required width $b$ and depth $h$.

This method, compared to the traditional one-time pass, is realized with less energy due to the fact that the process itself is performed at twice the speed with the same quality of the marking. The use of modern scanners allows achieving marking speeds (relative displacement of the beam relative to the work surface) of the order of 3$4 \mathrm{~mm} / \mathrm{s}$.

\section{B. Marking by hatching of the symbols}

Shading at two different angles is used to increase the contrast and quality of the laser marking. Thus, in reflected light, a greater contrast of the treated surface is obtained as a result of the diffuse scattering of light by multiple reflection centres. Marking with very good 
quality is obtained by writing strokes at angles $0^{\circ}, 75^{\circ}$ and $150^{\circ}$ relative to a given axis of processing. In Fig. 1 is a photograph of such a CuBr MOPA laser marking on an aluminium plate (Al-1050) and Fig. 2 shows a photograph of the same marking taken under magnification using an “Optica B-150” metallographic microscope.

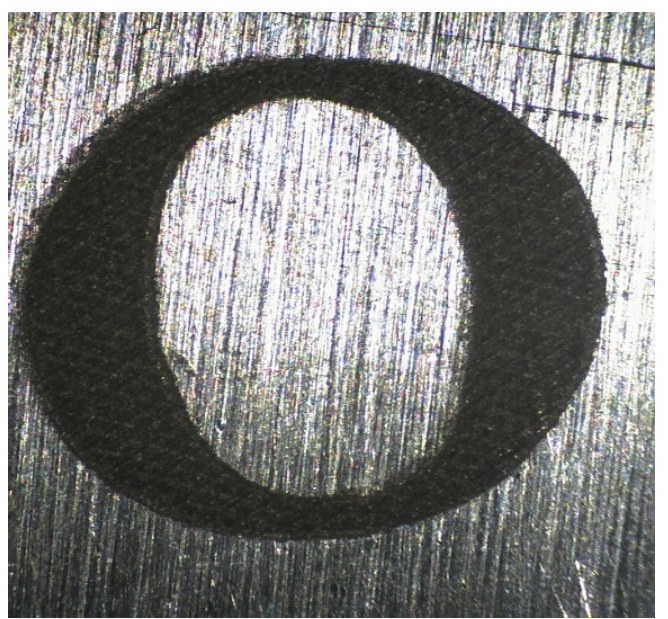

Fig. 1. CuBr MOPA laser marking on an aluminium plate.

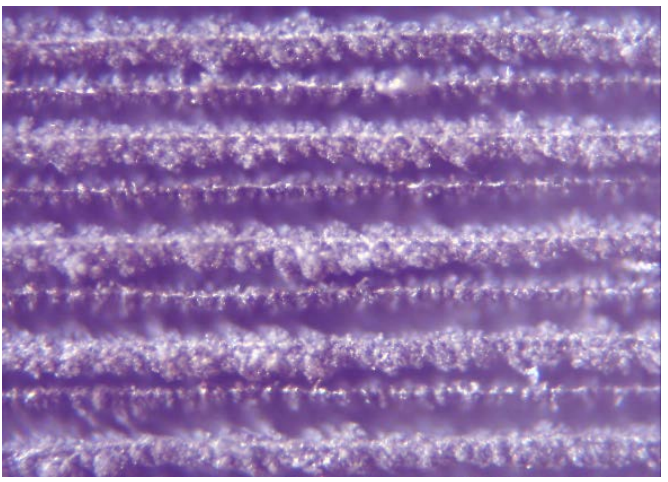

Fig. 2. Thesame marking taken under magnification using an optical microscope.

\section{EXPERIMENTAL SET UP AND PROCEDURE}

A series of experiments will be performed with a change in the marking speed and the number of repetitions on samples of Aluminum 1050. The obtained results will be analyzed, examining the change of the reflection coefficient and the change of the contrast of the processed samples depending on the variation of marking parameters.The experimental methods and testing of engraving of materials were prepared in laboratories of laser centre of Pulslight ltd. and Institute of Electronics, BAS-Sofia.

- Movement of the laser beam was achieved by an ARGES X-Y scanner (see device 2 on Fig.3).

- During the experiment the laser beam was focused perpendicular onto the sample surface with an FTheta objective (see device 3 on Fig. 3 ) $(\mathrm{f}=30 \mathrm{~cm}$ ) because of that only one laser line was applicable. In the experiments we used the green laser line $(511 \mathrm{~nm})$ because the focusing system was not achromatic. The focal spot after the scanner was $40 \mu \mathrm{m}$ in diameter.

The control of the laser complex was achieved by a special Master Timing System (MTS). This PC controlled tool was aimed at synchronizing the work of the laser oscillator and the power amplifier. It also played the role of an optical shutter by controlling the delay time. PC also controlled the ARGES scanning system.

The laser engraving machine CBL-MOPA10 and software Arges InScript were used for the experimental testing of three types of materials at various parameters (Fig.3).

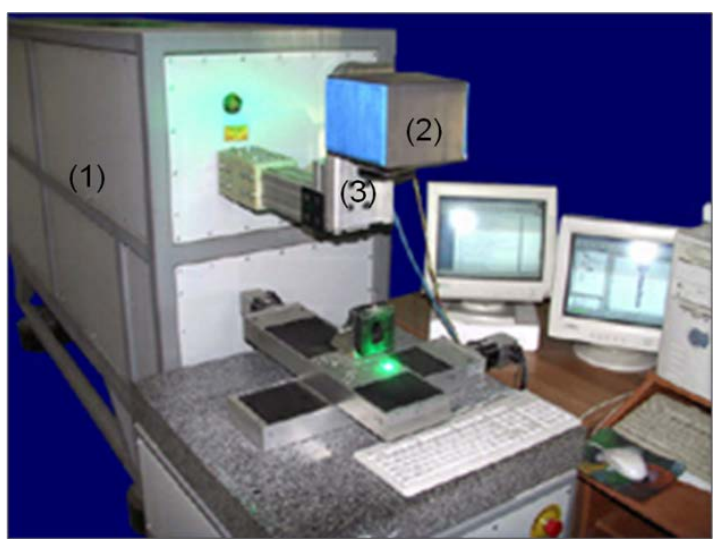

Fig. 3. The laser engraving machine CBL-MOPA10.

TABLE 1.TECHNICAL SPECIFICATION OF MOPA LASER SYSTEM

\begin{tabular}{|c|c|}
\hline wavelength & $510,6 \mathrm{~nm}$ and $578,2 \mathrm{~nm}(2: 1)$ \\
\hline Average power & $10 \mathrm{~W}$ \\
\hline $\begin{array}{c}\text { Pulse repetition } \\
\text { rate }\end{array}$ & $20 \mathrm{kHz}-$ fundamental \\
\hline Pulse energy & $0.5 \mathrm{~mJ}$ \\
\hline Beam diameter & $20 \mathrm{~mm}$ \\
\hline Beam divergence & $0.1 \mathrm{mrad}$ \\
\hline $\begin{array}{c}\text { Quality of beam } \\
\mathbf{M}^{2}\end{array}$ & $<1.5$ \\
\hline Duration of pulse & $30 \mathrm{~ns}$ \\
\hline
\end{tabular}

During the proposal of the experiment we used the Arges InScript system to find right laser settings for tested materials. In the proposed experiment were chosen laser parameters and testing materials and suggested also the laser beam ways/run through the testing field and how the laser beam will run through the sample considering to the first setting. During the engraving by laser beam, the pattern of engraving determines:

- the angle of the incident beam at engraving is 90 degrees,

- number of repetitions-determined number of times the laser beam passes over a given quadrant,

- sample lines pitch $0.05 \mathrm{~mm}$, 


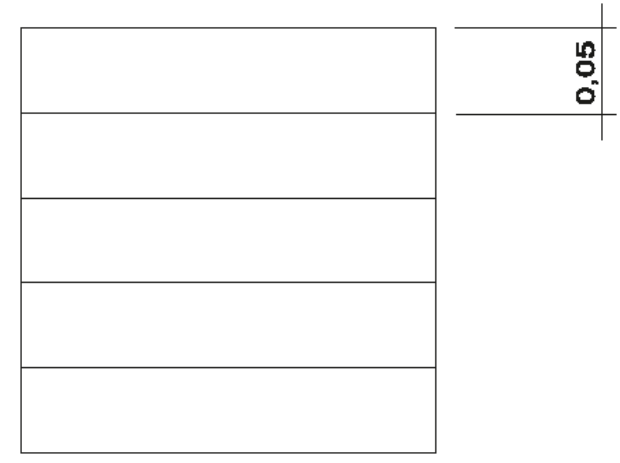

The track of pitch at the engraving $\Delta \mathrm{x}=0.05 \mathrm{~mm}$

During the experiment was used material - aluminium 1050A, chemical properties are shown in the Table 2.

TABLE 2. CHEMICAL PROPERTIES OF ALUMINUM 1050A

\begin{tabular}{|c|c|}
\hline Cu & $\max 0.05$ \\
\hline $\mathbf{M n}$ & $\max 0.05$ \\
\hline $\mathbf{S i}$ & $\max 0.25$ \\
\hline $\mathbf{F e}$ & $\max 0.40$ \\
\hline $\mathbf{M g}$ & $\max 0.50$ \\
\hline $\mathbf{Z n}$ & $\max 0.07$ \\
\hline $\mathbf{T i}$ & $\max 0.03$ \\
\hline $\mathbf{A l}$ & $\max 99.5$ \\
\hline
\end{tabular}

TABLE 3. MECHANICAL AND PHYSICAL PROPERTIES OF ALUMINUM 1050A

\begin{tabular}{|c|c|}
\hline $\begin{array}{c}\text { Tensile Strength } \\
\text { (MPa) }\end{array}$ & 75 \\
\hline $\begin{array}{c}\text { Proof Stress 0.2\% } \\
\text { (MPa) }\end{array}$ & 35 \\
\hline $\begin{array}{c}\text { Fatigue Strength 50 } \\
\text { mil. cycles (MPa) }\end{array}$ & 20 \\
\hline $\begin{array}{c}\text { Hardness Vickers } \\
\text { (HV) }\end{array}$ & 22 \\
\hline Hardness Brinell & 32 \\
\hline Elongation \% 50mm & $2.79 \mathrm{Kg} / \mathrm{m}^{3}$ \\
\hline Density & $640{ }^{\circ} \mathrm{C}$ \\
\hline Melting Point & $121-193 \mathrm{~W} / \mathrm{m} . \mathrm{K}$ \\
\hline $\begin{array}{c}\text { Thermal } \\
\text { Conductivity }\end{array}$ & $23.1 \times 10^{\wedge}-6 / \mathrm{K}$ \\
\hline $\begin{array}{c}\text { Modulus of } \\
\text { Elasticity }\end{array}$ & \\
\hline
\end{tabular}

- Format of $\mathrm{Al}$ samples for laser treating: $1 \times 1 \mathrm{~cm}^{2}$ pieces, $2 \mathrm{~mm}$ thick

- We moved the laser beam to draw parallel lines with distances of $50 \mu \mathrm{m}$, almost equal to the laser spot size.

The treatment was done with 5 repetitions (A, B, C, D and $\mathrm{E}$ ) and scanning beam velocities of 2, 5, 10, 20, 50,100, and $200 \mathrm{~mm} / \mathrm{s}$.

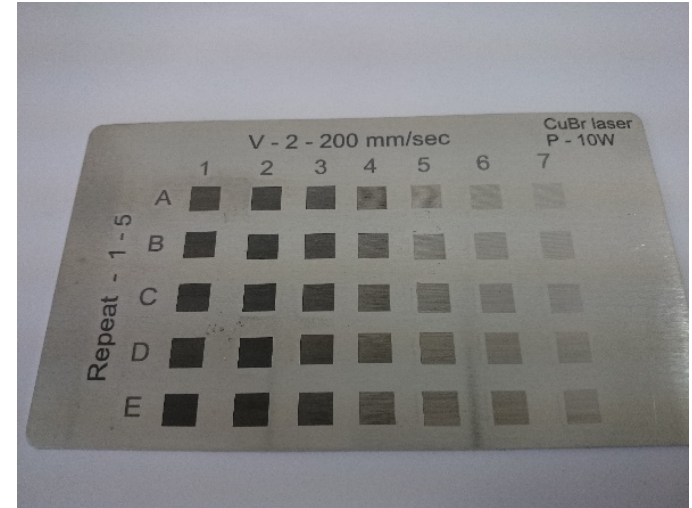

Fig. 4. The sample from Aluminum 1050A material with defined parameters.

A laser marked sample is created with a grid of $10 \times 10$ mm squares. Two technical parameters of laser system are varied within this grid, scanning speed (from 2 to 200 $\mathrm{mm} / \mathrm{s}$ ) and number of marking repetitions (from 1 to 5). The surface of Al sample with all squares is shown in figure 4. This figure shows how the surface contrast changes for each square in the matrix. An increase in contrast is observed with a decrease in scanning speed and increase of repetitions of laser marked lines.

\section{OTHER RESULTS AND DISCUSSION}

With the help of the Image pro plus program we study the intensity of the reflected light at different parameters of laser processing. The ratio between treated and untreated surface in percent gives us an idea of the result obtained by changing the speed and number of repetitions on the treated aluminium substrate.

Definition of contrast in case of dark markings on a lighter background

$$
k=\frac{J_{f}-J_{x}}{J_{f}} .100 \%
$$

where $J_{f}$ is the intensity of the reflected light from the untreated surface of the sample (from the background), $\mathrm{J}_{\mathrm{x}}$ is the intensity of the reflected light from the zone of influence on the sample.

In Fig.5, 6, 7 and 8 shows the graphical parameter "Ia" in percent's - intensity ratio of reflected light between the treated and untreated surface depending on the number of repetitions and scanning speed for aluminium A105. Intensity ratio is inversely proportional to the contrast of the laser marking. Therefore, a decrease in this indicator indicates the production of more contrast and quality marking. Repeated writing of the symbols results in about 25-30\% lower reflected intensity obtained by marking compared to single marking. The result obtained is explained as follows. Because the speed of writing the symbols is twice as fast as writing them once, the falling energy in the impact zone is the same. However, the energy absorbed is different in the two ways of laser marking. In the case of a single mark, the 
absorption capacity for the aluminium 1050 sample at this wavelength $\lambda=511 \mathrm{~nm}$ is $\mathrm{A}=30 \%$. With double marking at the first writing of the symbols the absorption capacity is the same, but at the second writing of the symbols it becomes $\mathrm{A}=65 \%$. The reason for the increase in the absorbency of this aluminium sample is that after the first writing of the symbols on the surface in the impact zone an oxide layer is formed and also increased roughness leading to diffuse reflection of light and more contrast marking.

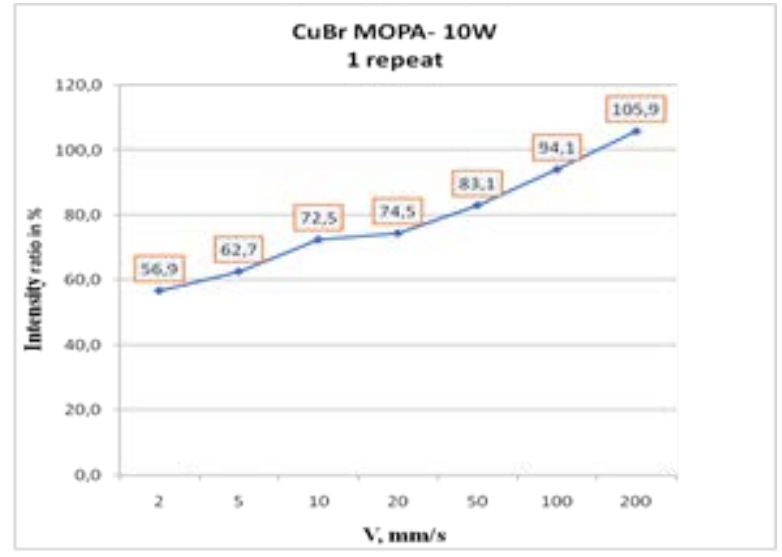

Fig. 5. Dependance of reflection of the light from scanning speed in case of 1 repeatition.

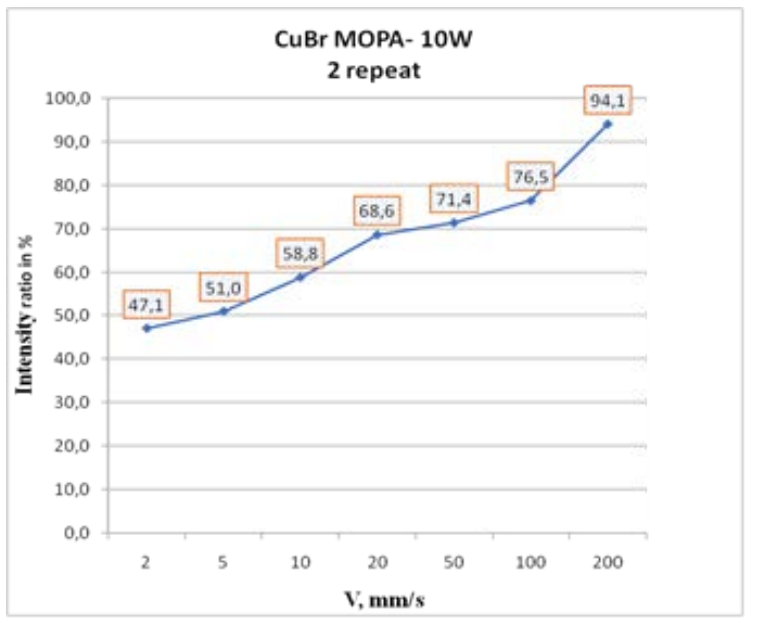

Fig. 6. Dependance of reflection of the light from scanning speed in case of 2 repetitions.

In FIG.7 and 8 shown the change in the intensity of the reflected light when marking an aluminium detail with a $\mathrm{CuBr}$ laser, power 10W, scanning speed respectively10 and $2 \mathrm{~mm} / \mathrm{s}$, repetitions from 1 to 5 . We can see that at lower scanning speed obtain lower parameter of intensity, which means more contrast and quality marking.

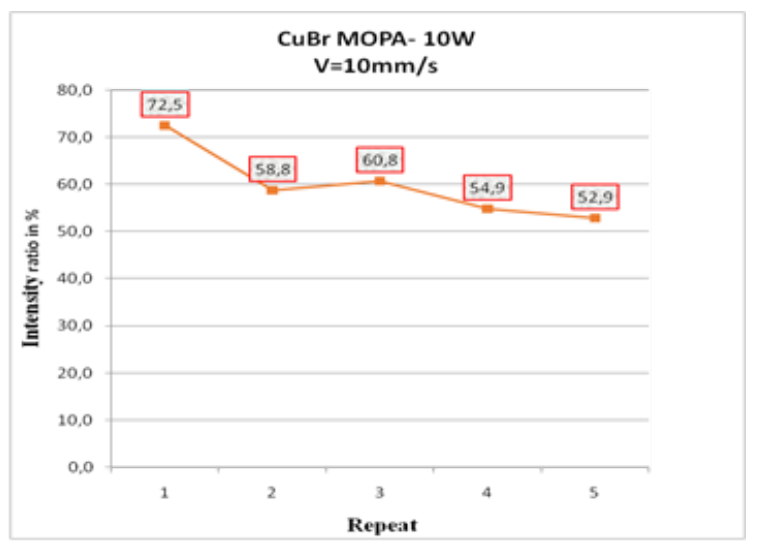

Fig. 7. Dependance of reflection of the light from repetitions in case of scannig speed $10 \mathrm{~mm} / \mathrm{s}$.

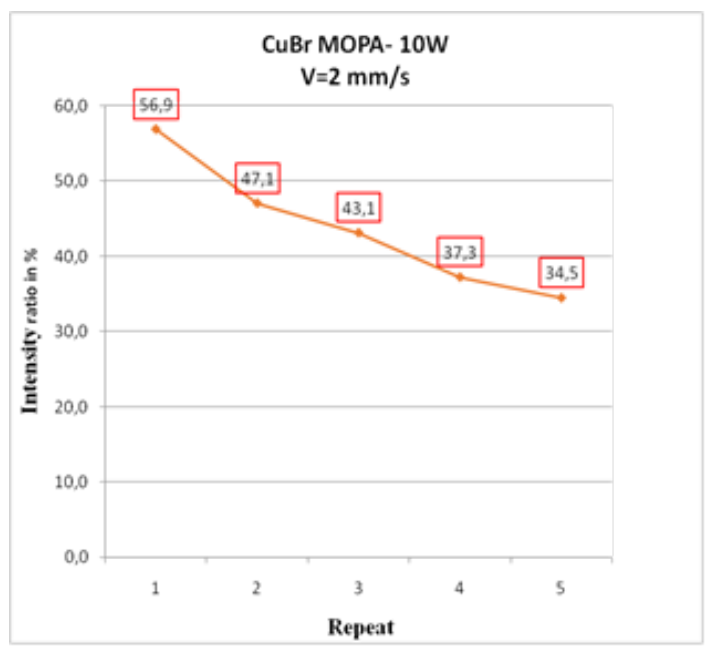

Fig. 8.

\section{CONCLUSIONS}

The optimization of the laser marking of Aluminum products requires for each specific case to determine the most appropriate way of marking with the optimal parameters of the laser and the technological process. It is of great importance for achieving high productivity with good quality laser marking.

Reducing the energy invested in production per unit of output, is great challenge in the modern industry. When characters are displayed twice (or repeatedly), in addition to improving efficiency marking through economy of energy, the possibilities of technical ecological system in terms of width and the depth of the marked symbols and the growth of marking at a specific denomination of laser power.

Achieving high quality brands is essential, but it must achieve an optimal ratio between durability and quality of markings on the one hand and its cost on the other. 
Environment. Technology. Resources. Rezekne, Latvia Proceedings of the $13^{\text {th }}$ International Scientific and Practical Conference. Volume 3, 20-24

\section{REFERENCES}

[1] Angelov N., L. Lazov, A. Atanasov Increasing the efficiency of laser marking of tool steel by double writing the symbols, International Scientific Conference UNITECH'08, Gabrovo, November 21-22, 2008

[2] Lazov L, Angelov N, Teirumnieks E, Teirumnieka E 2019 Proceedings of the 12th International Scientific and Practical Conf. 3 137-142

[3] Lazov L, Teirumnieks E, Angelov N, Teirumnieka E 2019 Proceedings of the 12th International Scientific and Practical Conf. 3 134-136

[4] Balchev I, Lazov L, Teirumnieks E 2019 Proceedings of the 12th International Scientific and Practical Conf. 3 13-17
[5] Lazov L, et al. 2015 Proceedings of the 10th International Scientific and Practical Conf. 1 108-115

[6] N.V. Sabotinov 1996 Pulsed Metal Vapour Lasers NATO ASI Series 1/5, Kluwer Academic Press. 113-124

[7] Sabotinov N, Bergmann H, Salimbeni R, Mizeraczyk J, Wallimann C, Kostadinov I 2002 Development of a System Based on a High Power and High Efficiency Copper Bromide Laser for Precision Materials Processing, Project NATO SfP 972685 „NATO SfP - Copper Bromide Laser”

[8] Angelov N. Optimizaciya na procesa markirane s lazerno lichenie na obrazci ot instrumentalna stomana. Disertacionen trud za pridobivane na stepen doktor. TU-Gabrovo, 2011 (in Bulgarian) 